\title{
OS DISCURSOS PROGRAMÁTICOS DOS PARTIDOS POLÍTICOS NA AMÉRICA LATINA: IDENTIDADE DE CLASSE E POLÍTICA ECONÔMICA
}

\section{Augusto Neftali Corte de Oliveira ${ }^{1}$}

\begin{abstract}
Resumo
0 artigo desenvolve uma análise comparada do discurso programático contemporâneo de 19 partidos de esquerda da América Latina, compreendendo 15 países. Quatro preocupações guiam o desenvolvimento da pesquisa: (a) a identidade com a classe trabalhadora está presente nas bases ideológicas destes partidos?, (b) estes partidos defendem uma agenda econômica social-democrata?, (c) existe relação entre a identidade de classe e a defesa de políticas socialdemocratas?, e (d) existe um padrão no discurso programático da esquerda latino-americana atual? Com foco na década de 2000, a pesquisa utiliza como fonte os programas de governo dos partidos e realiza breves discussões teóricas com a literatura especializada nos campos abordados. São encontrados elementos que permitem inferir a existência de relação positiva entre a ênfase de classe e a proposição de uma política econômica orientada por valores social-democratas, bem como um padrão comum que reúne um grupo significativo de partidos latino-americanos.
\end{abstract}

Palavras-chave: Partidos políticos. Identidade de classes. Política econômica social-democrata. América Latina.

\footnotetext{
${ }^{1}$ Mestre e doutorando em Ciência Política na Universidade Federal do Rio Grande do Sul. ancolive@gmail.com

Agradeço aos dois pareceristas anônimos de Mediações pelas importantes contribuições e destaco que os erros e imprecisões remanescentes são de minha responsabilidade.
} 


\title{
THE PROGRAMMATIC DISCOURSES OF POLITICAL PARTIES IN LATIN AMERICA: CLASS IDENTITY AND ECONOMIC POLICY
}

\begin{abstract}
This article develops a comparative analysis of the contemporary programmatic discourse of 19 left-wing political parties in Latin America, including 15 countries. Four concerns guide the development of this research: (a) is the identification with the working class present in the ideological bases of these parties? (b) do these parties advocate a social-democratic economic agenda?, (c) is there a relationship between class identity and the proposition of social democratic policies, and (d) is there a pattern in the programmatic discourse of the Latin American left-wing parties today? Focusing on the 2000s, the research resorts to the government programs published by the parties and holds brief discussions with the theoretical literature in the fields covered. The research found elements to infer the existence of a positive relationship between the emphasis on the working class and the proposition of an economic policy oriented by social-democratic values, as well a common pattern that brings together a significant group of Latin American political parties.
\end{abstract}

Keywords: Political parties. Class identity. Social democratic economic policies. Latin America.

\section{INTRODUÇÃ̃O}

$\mathrm{D}$ esde o início do Século XX, superando as clivagens sociais de cunho religioso ou nacional, a oposição entre capital e trabalho passou a ocupar um espaço central nas disputas políticas das sociedades ocidentais, especialmente nas democracias liberais europeias (LIPSET; ROKKAN, 1992). A oposição entre capital e trabalho se tornou importante não apenas para a formação dos grupos políticos - sindicatos, partidos socialistas, social-democratas e afins -, mas também para a estruturação da ação estatal com a definição de políticas econômicas e sociais. Nos trinta anos que se seguiram ao pós-guerra (1945), em meio à ascensão destes grupos políticos, foram construídos regimes de bem-estar social que mitigaram, de diferentes formas, a desigualdade entre trabalhadores e proprietários.

A partir das proposições de Keynes, a intervenção econômica voltada para a proteção do emprego e redistribuição das riquezas se tornou o objetivo central do movimento social-democrata europeu (PRZEWORSKI, 1989; NOTERMANS, 
2000; ESPING-ANDERSEN, 1998). Não obstante, a partir da década de 1970 se difundiu a percepção de que as raízes sociais dos partidos de esquerda junto à classe trabalhadora estariam se enfraquecendo. Ao mesmo tempo, os regimes de bem-estar passaram a ser atacados por possuírem efeitos prejudiciais sobre a reinversão econômica no processo produtivo. A adoção de medidas neoliberais tenderam a diminuir a capacidade dos estados europeus para proteger o emprego e manter políticas de bem-estar generosas.

Considerando o atual período democrático na América Latina, observase que a inserção dos partidos de esquerda nos sistemas políticos de diferentes países ocorreu em meio ao processo de avanço da normatividade neoliberal. Com regimes de bem-estar deficitários - em que grandes contingentes da população permaneceram, ao longo da história, excluídas seja da provisão de proteção social pública, seja de relações de trabalho estáveis - as reformas que diminuíram a capacidade do Estado em atuar no processo econômico se tornaram ainda mais onerosas para a classe trabalhadora. 0 presente artigo busca contribuir para identificar a permanência, entre os partidos políticos de esquerda latinoamericanos contemporâneos, de valores ligados à identidade de classe e à proposição de políticas tradicionalmente adotadas pelos movimentos socialdemocratas europeus. Ou, ao contrário, a adoção por estes partidos de preceitos neoliberais quanto à condução da política econômica.

Como guias para a pesquisa, foram formulados quatro questionamentos: A identidade com a classe trabalhadora está presente nas bases ideológicas dos partidos de esquerda latino-americanos contemporâneos? Estes partidos adotaram as diretrizes do Consenso de Washington ou foram capazes de defender uma agenda econômica próxima aos exemplos da social-democracia europeia? É possível inferir uma relação entre a identidade de classe e a defesa de políticas social-democratas? Por fim, existe uma esquerda latino-americana ou padrões de esquerda no que concerne ao discurso programático?

Para responder estas perguntas, apresentam-seneste artigo duas investigações: (a) sobre a existência de apelo à classe trabalhadora no discurso programático dos partidos de esquerda latino-americanos e (b) em que medida o discurso programático dos partidos aderem ao modelo de política econômica social-democrata ou neoliberal. Ao cruzar os dados destas duas dimensões, surge a oportunidade de observar a existência de relação entre a ênfase de classe e de política econômica na esquerda latino-americana e comparar como os diversos partidos se posicionam nestes temas. É necessário destacar que a pesquisa recorre exclusivamente aos programas de governos partidários e, portanto, menos do que respostas conclusivas 
sobre as questões levantadas, apresenta uma interpretação limitada a este foco de análise. A pesquisa não exclui outros pontos de vista sobre o tema - por exemplo, a partir da composição social ou da opinião de membros e líderes dos partidos - que podem apresentar diferentes elementos para sua interpretação.

Na seção seguinte, são apresentadas as definições teóricas e metodológicas que guiam a seleção dos casos e embasam as ilações apresentadas no decorrer do artigo.

\section{CASOS E PROCEDIMENTOS DA PESQUISA}

A seleção dos casos foi orientada por três preocupações: a possibilidade de identificar o campo ideológico independentemente dos eventuais resultados da análise empírica, a relevância do partido no sistema político em que ele se insere e o acesso aos documentos partidários que são utilizados como fonte. Para vencer a primeira etapa, optou-se por selecionar os casos conforme a vinculação das agremiações a duas organizações internacionais: o Foro de São Paulo e a Internacional Socialista ${ }^{2}$ (nos casos em que não existe partido vinculado ao Foro ou em que esta agremiação é relativamente pequena). A relevância das agremiações no sistema político foi observada a partir de sua inserção parlamentar e no executivo de cada país. Para dois países foram selecionados partidos de inserção limitada: na Argentina o Partido Socialista e no Paraguai o Partido País Solidário, que participa do governo Lugo sem ter representação parlamentar. Neste caso seria importante contemplar ao menos o Partido Popular Tekojoja, mas não foi possível obter um documento programático válido. No restante dos países, os partidos correspondem aos mais relevantes do campo da esquerda socialista - mas a pesquisa não inclui partidos radicais ou democratas cristãos, por exemplo.

0 conjunto completo foi composto por nove partidos associados ao Foro de São Paulo (entre eles o Movimiento al Socialismo Boliviano, convidado), cinco partidos vinculados à Internacional Socialista e outros cinco com as duas vinculações. A pesquisa cobre 15 países, entre eles todos os sul-americanos com exceção da Guiana e Suriname, mais El Salvador, Guatemala, México, Nicarágua e um país caribenho, a República Dominicana. Além dos 19 casos de partidos de esquerda foram estudadas três agremiações associadas a uma organização de direita, a Internacional Democrat Union ${ }^{3}$, com finalidade de controle.

\footnotetext{
${ }^{2}$ Foram consultados os sítios na internet do Foro de São Paulo <http://forodesaopaulo. org/?page_id=52> e da Internacional Socialista <http://www.socialistinternational.org/ viewArticle.cfm?ArticlePageID=931>, em 15 de janeiro de 2011 .

${ }^{3}$ Foi consultado o sítio na internet da Internacional Democrat Union <http://www.idu.org/ member.aspx>, em 15 de janeiro de 2011.
} 
Para os partidos nenhum outro documento é tão abrangente quanto os programas de governo, nem capaz de apresentar as preferências do partido como um todo - e não de seus candidatos ou facções isolados. Por esta razão, deu-se preferência a este tipo de documento sempre que fosse aprovado por uma instância partidária (como o congresso) ou, em sua falta, um programa eleitoral de candidato exclusivo do partido, não de coalizões. Considerando o interesse da pesquisa em apresentar uma fotografia atual das relações entre o discurso de classe e de política econômica, foram selecionados os documentos que os partidos disponibilizaram mais recentemente e, exclusivamente, no curso da década de 2000.

É necessário compreender, como limite da pesquisa, que existe um longo caminho entre o discurso programático dos partidos e a política pública. 0 Chile e o Brasil oferecem bons exemplos: para favorecer seus candidatos presidenciais com coalizões mais amplas e maior apelo eleitoral, PS e PT realizaram importantes abdicações nos programas aprovados pelos partidos (OLIVEIRA, 2009). Via de regra, os programas de suas coalizões eleitorais foram bastante mais moderados do que os aprovados nos congressos partidários. Assim, objetivos ideológicos dos partidos são balanceados, mas não necessariamente superados, pela expectativa da vitória eleitoral e da conquista de cargos políticos. Mesmo considerando o programa eleitoral, o exercício do governo leva ainda a outras contingências: da disponibilidade de recursos financeiros, da estrutura das políticas públicas existentes, da conjuntura das forças políticas, sociais e econômicas. 0 discurso programático dos partidos deve ser compreendido, portanto, como base para a atuação das agremiações na formação de coalizões, nas disputas eleitorais e para influenciar as políticas públicas - mas não possui um impacto imediato na ação estatal.

Klingemann, Hofferbert e Budge (1994, p. 22) definem três formas de apresentação dos programas de governo: (a) publicação que detalha exaustivamente as propostas do partido; (b) pronunciamento do líder partidário ou candidato diretamente à imprensa; e (c) conjunto de publicações tratando de matérias específicas. Os programas dos partidos latino-americanos podem ser separados ainda segundo duas características. Quanto à sua natureza, entre (a) princípios ou proposições mais genéricas sobre a atuação do partido, e (b) programa com propostas direcionadas para a disputa eleitoral. Quanto à origem, entre (a) aqueles que são aprovados pelo partido, geralmente durante um congresso, e (b) aqueles que são formulados por equipes designadas para esta tarefa pelos líderes partidários.

Nos 22 partidos selecionados se observam majoritariamente publicações detalhadas, com uma média de 70 páginas por documento, embora variem 
bastante: o menor é o do PPS paraguaio, com apenas oito, e o maior é o do PLD, com 176. Apenas a FSLN apresentou um programa sob a forma de discurso, um longo pronunciamento do líder sandinista Daniel Ortega. 0 documento mais sui generis selecionado foi o da guatemalteca UNE, que utiliza muitas imagens e representações esquemáticas. No quadro abaixo são identificados os tipos de documento conforme sua natureza (19 programas de governo e três documentos de princípios) e origem (nove documentos aprovados em congressos e 13 programas de governo formulados por equipes técnicas, via de regra destinados às eleições).

\begin{tabular}{|c|c|c|c|c|c|}
\hline \multicolumn{6}{|c|}{ Quadro 1 - Partidos, associação e programas de governo } \\
\hline País & Sigla & Partido & Filiaçãa & Documento & Ano \\
\hline Argentina & PS-Ar & Partido Socialista & FSP - IS & Programa/Cong. & 2010 \\
\hline Bolívia & MAS-Bo & Movimiento al Socialismo & FSP & Programa/Tec. & 2005 \\
\hline Brasil & PT-Br & Partido dos Trabalhadores & FSP & Programa/Cong. & 2010 \\
\hline \multirow{2}{*}{ Chile } & PPD-Ch & Partido por la Democracia & IS & Princípios/Cong. & 2003 \\
\hline & PS-Ch & Partido Socialista & FSP - IS & Programa/Cong. & 2008 \\
\hline \multirow{2}{*}{ Colômbia } & PLC-Co & Partido Liberal Colombiano & IS & Programa/Tec. & 2010 \\
\hline & POLO-CO & Polo Democrático Alternativo & FSP & Princípios/Cong. & 2009 \\
\hline Equador & PAIS-Eq & Movimiento PAÍS & FSP & Programa/Cong. & 2010 \\
\hline El Salvador & FMLN-ES & $\begin{array}{l}\text { Frente Farabundo Martí para la } \\
\text { Liberación Nacional }\end{array}$ & FSP & Programa/Tec. & 2009 \\
\hline Guatemala & UNE-Gu & Unidad Nacional de la Esperanza & IS & Programa/Tec. & 2006 \\
\hline \multirow{2}{*}{ México } & PRD-Me & Partido de la Revolución Democrática & FSP - IS & Programa/Cong. & 2009 \\
\hline & PRI-Me & Partido Revolucionario Institucional & IS & Programa/Tec. & 2009 \\
\hline Nicarágua & FSLN-Ni & Frente Sandinista de Liberación Nacional & FSP - IS & Programa/Tec. & 2006 \\
\hline Paraguai & PPS-Pa & Partido País Solidário & FSP - IS & Princípios/Cong. & 2002 \\
\hline \multirow{2}{*}{ Peru } & APRA-Pe & Partido Aprista Peruano & IS & Programa/Tec. & 2006 \\
\hline & PNP-Pe & Partido Nacionalista del Peru & FSP & Programa/Tec. & 2006 \\
\hline $\begin{array}{l}\text { República } \\
\text { Dominicana }\end{array}$ & PLD-RD & Partido de la Liberación Dominicana & FSP & Programa/Tec. & 2000 \\
\hline Uruguai & FA-Ur & Frente Amplio & FSP & Programa/Tec. & 2009 \\
\hline Venezuela & PSUV-Ve & $\begin{array}{l}\text { Partido Socialista Unificado de } \\
\text { Venezuela }\end{array}$ & FSP & Programa/Cong. & 2010 \\
\hline Chile & UDI-Ch & Unión Demócrata Independiente & IDU & Programa/Tec. & 2005 \\
\hline El Salvador & ARENA-ES & Alianza Republicana Nacionalista & IDU & Programa/Tec. & 2004 \\
\hline Peru & PPC-Pe & Partido Popular Cristiano & IDU & Programa/Tec. & 2005 \\
\hline
\end{tabular}

A abordagem do discurso programático dos partidos políticos possui tradição na ciência política. 0 principal desafio deste tipo de pesquisa éestabelecer categorias que possam ser utilizadas para os programas de diversos partidos e para as políticas efetivamente adotadas. A presente pesquisa se preocupa com a comparatividade 
entre os programas, deixando a possibilidade de observar a ação estatal para uma oportunidade futura. A pesquisa desenvolvida por Klingemann, Hofferbert e Budge (1994) utiliza como base teórica para a análise dos programas a Saliency Teory. Esta teoria sugere que os programas de governo abordam apenas os assuntos que os partidos consideram relevantes, declinando expressamente uma posiç̧ão nestes casos; já em outras questões simplesmente não se manifestam (KLINGEMANN; HOFFERBERT; BUDGE, 1994, p. 22). Nesse sentido, os autores apontam que os partidos que competem entre si não costumam apresentar políticas diferentes para os mesmos assuntos: apenas enfatizam os assuntos que são favoráveis e não citam os pontos aos quais são contrários. A partir da conexão destes pontos em que os partidos se manifestam, torna-se possível identificar o posicionamento geral do partido em uma determinada dimensão (por exemplo, na dimensão econômica) e compará-los em um sistema partidário ou entre diversos países.

0 procedimento da pesquisa de Klingemann, Hofferbert e Budge (1994, p. 36) consiste em contar as sentenças dos programas de governo que se enquadram em 54 categorias definidas em sete grupos (liberdade e democracia, economia, welfare e qualidade de vida, etc.). Desta maneira, os autores avaliam se os programas conferem ênfase às categorias definidas, considerando o espaço do programa dedicado a cada tema. Algumas das categorias dos autores são positivas ou negativas, mas - em conformidade com a teoria da saliência - ênfases negativas foram pouco percebidas. No silêncio do programa, uma determinada categoria pode ficar vazia. Para compor a escala ideológica dos partidos, os autores simplesmente somam o espaço dedicado às ênfases que possuem uma orientação de esquerda (regulação do capitalismo, planejamento econômico, pró-trabalho) e descontam o espaço das ênfases de direita (liberdade de empresa, ortodoxia econômica, incentivos econômicos).

A presente pesquisa utiliza 10 variáveis para identificar a presença da "luta de classes" nos programas de governo e outras 20 variáveis para definir "política econômica", sendo que 10 se referem a temas social-democratas e outras 10 a temas liberais. Entretanto, diferente de Budge e colaboradores, esta pesquisa considera como ênfase se, no curso do programa, consta pelo menos uma proposta que implique na defesa de determinado tema. Portanto, são 30 variáveis dicotômicas que relatam a presença ou a ausência de cada tema no discurso programático analisado. Não foram estabelecidas categorias negativas, mas existe um antagonismo entre as propostas dos dois campos da política econômica. Assim, 
os partidos podem possuir ênfases contraditórias (como protecionismo e abertura comercial).

Um exemplo do procedimento adotado: se o programa defende que 0 sistema tributário deve ser mais justo, que quem ganha mais deve pagar mais (como faz o programa da FSLN), dá-se à variável "progressividade da tributação" o valor "presente", ou "1". A FSLN enfatiza "progressividade da tributação" em seu programa. Este procedimento parece adequado, ao invés de considerar a relevância quantitativa de cada matéria no documento, pois os partidos podem apresentar em um espaço restrito, não mais do que uma ou duas sentenças, toda uma agenda econômica. Para os programas que apresentam introduções históricas ou discussões teóricas, procurou-se considerar apenas propostas objetivas de ação em relação às categorias de política econômica.

\section{Partidos e identidade de Classes na América Latina}

Lipset e Rokkan (1992, p. 182) consideram a oposição entre capital e trabalho, que surgiu da revolução industrial, como a última clivagem social que repercutiu na estrutura da vida política da Europa. Embora as oportunidades dos atores sociais ligados a esses campos tenham sido fortemente influenciadas pelas disputas políticas mais antigas, a clivagem capital/trabalho se tornou presente em todos os países de maneira bastante homogênea. A partir de sua consolidação, a mobilização dos trabalhadores fez surgir partidos que almejaram representar a classe e, mais do que isso, refletiram esta relação em sua composição social e em programas políticos abrangentes e ideologicamente coerentes (DUVERGER, 1970, p. 103-152). Embora também estivesse presente em partidos confessionais, foram, sobretudo, os partidos trabalhistas, socialistas e social-democratas que desenvolveram grandes organizações intrinsecamente relacionadas com a noção de pertencimento à classe trabalhadora.

Uma abordagem atual da conexão entre partidos e classes sociais procura estudar os efeitos do discurso de classe sem perder de vista os constrangimentos e as oportunidades estratégicas do ambiente político/eleitoral. Segundo Przeworski (1989, p. 121-160), os partidos de esquerda que ampliaram seu apelo programático em busca da maioria eleitoral, enfraquecendo o discurso de classe, acabaram por comprometer os vínculos políticos do operariado. Assim, a dinâmica eleitoral teria levado os partidos socialistas a um trade-off entre manter os vínculos de classe ou enfraquecê-los em favor de alianças amplas. 0 autor, portanto, sustenta que 
a classe social pode ser discricionariamente mobilizada pelos partidos políticos. Kitschelt (1993), por outro lado, aponta que as transformações socioeconômicas do pós-fordismo mudaram a estrutura do mercado eleitoral e lhe desvincularam do eixo socialismo-capitalismo. Para o autor, um eleitorado constituído a partir de múltiplos interesses, nos quais a inserção do indivíduo nas relações de produção é apenas um dos fatores, não apenas favorece um discurso programático não orientado pela noção de classe como compromete sua validade enquanto conceito de explicação do comportamento eleitoral.

Bem entendido, esta pesquisa não discute a validade sociológica do conceito de classe. Para a validade da idéia de classe social em termos ideológicos, como argumento mobilizador da disputa pelo poder político, conhecer sua utilização na prática, no dia-a-dia dos partidos, já é um passo importante. De fato, as mudanças observadas nos programas dos partidos são as evidências mais claras das transformações dos valores políticos relevantes para as democracias consolidadas (CLARK, 2003, p. 24). Neste momento a pesquisa busca observar a permanência, na esquerda latino-americana contemporânea, de um discurso voltado para a noção de classe.

Este discurso, tal como difundido pelo pensamento marxista, é necessariamente conflitivo. A classe trabalhadora se constitui em oposição à capitalista: "A sociedade toda cinde-se, cada vez mais, em dois grandes campos inimigos, em duas grandes classes que directamente se enfrentam: burguesia e proletariado" (MARX; ENGELS, 1997, p. 15). 0 espírito de ação dos partidos classistas também está inserido nesta dinâmica do conflito, pois se volta para a "formação do proletariado em classe, derrubamento da dominação da burguesia, conquista do poder político pelo proletariado" (MARX; ENGELS, 1997, p. 23). Observar o discurso de classe, mesmo que sob uma perspectiva expandida para além do proletariado, passa por observar o discurso da luta de classes.

Para averiguar se os partidos de esquerda latino-americanos nos dias de hoje aderem à noção de luta de casses, e em que medida eles aderem, foram utilizadas 10 variáveis baseadas nos seguintes temas: socialismo, revolução, capitalismo, trabalhadores, classe trabalhadora, burguesia, classe dominante, imperialismo, democracia econômica e justiça social. Com exceção dos últimos dois, são temas presentes no Manifesto Comunista de Marx e Engels ${ }^{4}$. Buscou-se identificar, em cada

${ }^{4}$ Embora não necessariamente vinculadas ao conceito de luta de classes, as ideias de justiça
social e democracia econômica exprimem o reconhecimento de um status quo injusto ou não

Os DISCURSOS PROGRAMÁTICOS DOS PARTIDOS POLÍTICOS...

A. Oliveira

- 209 
programa, a existência de ênfase nestes temas. Inicialmente, pensou-se em fazer correções caso o número de ênfases em luta de classe (índice de luta de classes, I-LC) não correspondesse a uma interpretação geral do discurso programático, o que acabou não sendo necessário. 0 I-LC parece ter capturado de maneira adequada 0 sentido geral dos documentos. 0 procedimento para analisar quantas ênfases foram destacadas em cada programa seguiu o estabelecido na seção acima.

0 resultado da análise sobre a presença da luta de classes nos discursos programáticos dos partidos de esquerda da América Latina se encontra no quadro abaixo.

\begin{tabular}{|c|l|c|}
\hline \multicolumn{3}{|c|}{ Quadro 2 - I-LC, partidos e nível da luta de classes } \\
\hline I-LC & \multicolumn{1}{|c|}{ Partidos } & Nível \\
\hline 9 & PAIS-Eq, PSUV-Ve & \multirow{2}{*}{ Elevado } \\
\hline 7 & MAS-Bo & \multirow{2}{*}{ Méio Elevado } \\
\hline 6 & POLO-Co & \multirow{2}{*}{ Médio Baixo } \\
\hline 5 & PRD-Me, PPS-Pa, PNP-Pe & \multirow{2}{*}{ Baixo } \\
\hline 4 & PS-Ar, FMLN-ES, PRI-Me, FSLN-Ni, PLD-RD \\
\hline 3 & PT-Br, PS-Ch, PPD-Ch, FA-Ur & \\
\hline 2 & PLC-Co, APRA-Pe, (ARENA-ES) & \\
\hline 1 & UNE-Gu, (UDI-Ch, PPC-Pe) & \\
\hline
\end{tabular}

A partir do I-LC, os partidos foram classificados em quatro níveis que apresentam algumas características em comum quanto ao discurso de luta de classes. 0 PAIS e o PSUV foram os únicos partidos a legitimar um discurso sobre a luta de classes num sentido amplo (nível elevado), próximo à tradição do Manifesto Comunista: uma relação de exploração na qual a classe proprietária dos meios de produção subjuga a classe trabalhadora e exerce dominação econômica e social. Cinco partidos se enquadram em uma visão mais restrita da luta de classe (médio elevado): percebem a existência de uma relação antagônica, no limite de exploração econômica da classe trabalhadora por um setor privilegiado da sociedade.

A maioria dos partidos analisados, nove casos, considera a existência de interesses divergentes que separam a classe trabalhadora e os proprietários (médio baixo). Estes partidos percebem interesses conflitantes que perpassam as relações de classe, setores ou grandes grupos sociais, mas não utilizam as idéias de exploração e dominação como fazem os classificados como médio elevado. Por fim, três partidos

democrático nas relações socioeconômicas. Na prática, apresentam-se como sucedâneos de slogans tradicionais nos discursos dos partidos de esquerda. 
de esquerda - todos ligados à Internacional Socialista - limitam-se a reconhecer que existem interesses específicos do grupo de pessoas que possuem relações laborais (nível baixo). Os três partidos de direita analisados também ficaram no menor I-LC, apenas reconhecendo interesses específicos. De fato, nenhum partido dentre os analisados deixou de fazer menção a este conjunto social: os trabalhadores.

Um dos objetivos desta pesquisa é avaliar se, após a abertura democrática e 0 avanço do neoliberalismo na década de 1990, o discurso programático dos partidos de esquerda da América Latina apela à identidade com a classe trabalhadora. Se esta identidade passa pela exposição em seus programas de um discurso coerente com a idéia de luta de classes, e se o I-LC foi capaz de apreender esta dinâmica, pode-se concluir favoravelmente a esta hipótese. Podem ser distinguidos quatro casos de resultados relativamente baixos (PT, PS-Ch, PPD e FA), uma concentração de oito agremiações que defendem entre quatro e sete ênfases de luta de classes e dois casos de resultados mais elevados (PAIS e PSUV). Mesmo após o propalado fim das ideologias, os partidos de esquerda da América Latina permanecem significativamente associados aos conceitos de distinção entre classes sociais.

\section{A POLÍTICA ECONÔMICA DOS PARTIDOS LATINO-AMERICANOS}

Przeworski ressalta que foi apenas após a Teoria Geral de Keynes que os partidos socialistas conseguiram compatibilizar seu discurso programático com a busca de maiorias eleitorais, pois o keynesianismo ofereceu razões técnicas para se acreditar que os interesses dos trabalhadores e dos pobres combinam com 0 interesse geral da sociedade. Em lugar do objetivo socialista tradicional (nacionalização da produção), ganhou força a idéia do bem-estar geral por meio da gestão da economia capitalista (nacionalização do consumo). 0 novo projeto reformista dos partidos de esquerda "era economicamente viável, socialmente benéfico e, talvez mais importante, politicamente praticável sob condições democráticas" (PRZEWORSKI, 1989, p. 55). Em termos de política econômica, os princípios keynesianistas não diferiam dos liberais por defender a intervenção estatal na economia. Como Notermans observa, toda política macroeconômica é intervencionista, o que muda são os objetivos que a orientam: para os liberais a política econômica deve ser indiscricionariamente voltada para o controle da inflação, para os social-democratas os valores de crescimento econômico e emprego podem ser considerados (NOTERMANS, 2000, p. 34). 
Segundo Esping-Andersen, os diferentes regimes de bem-estar social do pósguerra foram erigidos conforme a capacidade dos partidos de esquerda em formar coalizões e exercer o predomínio político (ESPING-ANDERSEN, 1998, p. 53). Para além das políticas sociais, estes regimes se caracterizavam com diferentes estruturas de interação entre estado e mercado na provisão da proteção social, especialmente no que diz respeito à busca do pleno-emprego. A força das organizações dos trabalhadores e os governos de esquerda estiveram fortemente associados à busca do pleno-emprego nas democracias desenvolvidas, e os governos de direita ao controle da inflação, pelo menos até a década de 1970 (ESPING-ANDERSEN, 1998, p. 186). Entretanto, Notermans destaca que a longo prazo todo governo precisa proteger a estabilidade dos preços, sob pena de ser punido nas urnas por incompetência. 0 autor defende que foram os constrangimentos da política monetária que, no lastro da crise de 1970, inviabilizaram o programa social-democrata e abriram espaço para o retorno da ortodoxia (NOTERMANS, 2000, p. 175).

Os países latino-americanos, por outro lado, receberam orientações normativas ortodoxas para condução da política econômica não apenas como medida para controlar a inflação, mas como ajustes institucionais favoráveis ao desenvolvimento. Como admite Rodrik (2006), sob os princípios do Consenso de Washington a América Latina e outras áreas subdesenvolvidas passaram pelas maiores reformas de liberalização econômica já registradas, mas seus resultados em termos de crescimento econômico ficaram muito aquém do esperado pelos órgãos internacionais entusiastas das reformas (Fundo Monetário Internacional e Banco Mundial). Mesmo sofrendo mudanças ao longo dos anos de 1990, o conjunto de políticas de liberalização englobadas sob o título de Consenso de Washington informou muito da articulação política latino-americana em termos econômicos. Tanto quando inspiração nos modelos social-democratas do pós-guerra, parece importante conhecer a posição dos partidos a respeito destas políticas de liberalização.

Neste sentido, para medir o grau de adesão dos partidos de esquerda latinoamericanos às políticas social-democratas foram elaborados dois grupos com dez variáveis cada: um de medidas que se ajustam às ideias keynesianas e/ou renegam as ideias ortodoxas (social-democratas, SD), e o segundo que condiz com o Consenso de Washington (liberais, LIB). 0 procedimento de análise dos programas seguiu as regras expostas na primeira seção do artigo. Os temas adotados são os seguintes. 


\begin{tabular}{|c|c|}
\hline \multicolumn{2}{|c|}{ Quadro 3 - Variáveis da política econômica } \\
\hline Variáveis social-democratas (SD) & Variáveis liberais (LIB) \\
\hline 1 Regulamentação das relações de trabalho & 1 Flexibilização das relações de trabalho \\
\hline 2 Utilização reguladora das empresas públicas & 2 Privatização de serviços \\
\hline 3 Nacionalização de empresas estratégicas & 3 Privatização de empresas \\
\hline 4 Protecionismo econômico & 4 Abertura econômica \\
\hline 5 Progressividade da tributação & 5 Restrição à tributação \\
\hline 6 Revisão dos contratos de dívida & 6 Disciplina fiscal/superávit \\
\hline 7 Keynesianismo/manutenção do consumo & 7 Restrição do gasto público \\
\hline 8 Crescimento econômico/geração de emprego & 8 Controle da inflação \\
\hline 9 Controle/intervenção no sistema financeiro & 9 Autonomia do Banco Central \\
\hline 10 Controle sobre a circulação de capitais & 10 Abertura ao investimento externo direto \\
\hline
\end{tabular}

0 quadro abaixo apresenta o total de ênfases de cada partido nas dimensões SD e LIB, o total de ênfases (somando as duas) e o valor no índice de socialdemocracia (I-SD), descontando o total de LIB do total de SD.

Tabela 1 - Ênfases de política econômica e I-SD por partido

\begin{tabular}{|l|c|c|c|c|l|c|c|c|c|}
\hline Partido & SD & LIB & Total & I-SD & Partido & SD & LIB & Total & I-SD \\
\hline PS-Ar & 5 & 0 & 5 & $\mathbf{5}$ & PRI-Me & 4 & 1 & 5 & $\mathbf{3}$ \\
\hline MAS-Bo & 6 & 0 & 6 & $\mathbf{6}$ & FSLN-Ni & 4 & 0 & 4 & $\mathbf{4}$ \\
\hline PT-Br & 5 & 1 & 6 & $\mathbf{4}$ & PPS-Pa & 4 & 0 & 4 & $\mathbf{4}$ \\
\hline PPD-Ch & 3 & 0 & 3 & $\mathbf{3}$ & APRA-Pe & 3 & 4 & 7 & $\mathbf{- 1}$ \\
\hline PS-Ch & 4 & 0 & 4 & $\mathbf{4}$ & PNP-Pe & 6 & 4 & 10 & $\mathbf{2}$ \\
\hline PLC-Co & 2 & 1 & 3 & $\mathbf{1}$ & PLD-RD & 4 & 6 & 10 & $\mathbf{- 2}$ \\
\hline POLO-Co & 7 & 0 & 7 & $\mathbf{7}$ & FA-Ur & 4 & 0 & 4 & $\mathbf{4}$ \\
\hline PAIS-Eq & 8 & 0 & 8 & $\mathbf{8}$ & PSUV-Ve & 7 & 0 & 7 & 7 \\
\hline FMLN-ES & 5 & 0 & 5 & $\mathbf{5}$ & UDI-Ch & 2 & 9 & 11 & $\mathbf{- 7}$ \\
\hline UNE-Gu & 2 & 3 & 5 & $\mathbf{- 1}$ & ARENA-ES & 0 & 5 & 5 & $\mathbf{- 5}$ \\
\hline PRD-Me & 7 & 0 & 7 & $\mathbf{7}$ & PPC-Pe & 0 & 8 & 8 & $\mathbf{- 8}$ \\
\hline
\end{tabular}

Os três partidos de direita, como esperado, apresentam um desempenho contrário aos partidos de esquerda: UDI, ARENA e PPC possuem os maiores índices negativos, indicando forte presença de ênfases LIB em seus programas. Este dado favorece a confiança na capacidade dos temas em apreender as preferências do discurso programático dos partidos e, portanto, em estabelecer distinções entre eles. 0 único partido que claramente extrapolou a capacidade dos temas estudados em apreender suas intençõesfoi o PSUV. O discurso programático do partido venezuelano não enfatizou três categorias SD: progressividade da tributação, manutenção do consumo e crescimento econômico. No primeiro caso, a falta de ênfase na tributação

Os DISCURSOS PROGRAMÁTICOS DOS PARTIDOS POLÍTICOS...

A. Oliveira $\bullet 213$ 
parece ser impacto da relevância do petróleo para as receitas do estado (PSUV-VE, 2010, p. 129). Mas o PSUV também realiza propostas que não são enquadráveis nas categorias definidas. Quanto às relações de consumo propõe "[d]iseñar e inventar nuevas formas de producción, distribución, circulación y consumo, que tiendan a eliminar la lógica del capital y la intermediación depredadora de los capitalistas" (PSUV-VE, 2010, p. 108). Sobre a busca de crescimento econômico, propõe que "la ruptura con el conocimiento y la racionalidad burguesa y su metafísica de la economía, particularmente lo atinente a las formas de contabilizar y cuantificar el desarrollo económico reduciéndolo a crecimiento. Esto incluye la propia noción de crecimiento" (PSUV-VE, 2010, p. 116).

Os outros partidos que obtiveram um valor positivo elevado no I-SD não possuem discursos semelhantes ao do PSUV. 0 PAIS desenvolve críticas às relações mercantis, defende outras formas de relações econômicas (não monetárias) e a democratização dos meios de produção (PAIS, 2010, p. 44), mas na prática suas propostas estão dirigidas para uma economia de mercado com intervenção estatal orientada para o crescimento econômico, a distribuição de riqueza e a criação de emprego. Os discursos programáticos do PRD, POLO e MAS também são bem apreendidos pelas categorias definidas na pesquisa. Estes cinco foram os partidos que obtiveram um I-SD de seis ou mais. Com um índice entre três e cinco, enquadram-se a maioria dos partidos: nove casos.

De todos os 13 casos com I-SD maior do que três, apenas o PT e o PRI realizaram uma ênfase LIB, e apenas uma cada um. 0 primeiro enfatizou 0 controle da inflação (estabilidade econômica) e o segundo a abertura econômica. Esta constatação revela que a maior parte dos partidos de esquerda da América Latina evita enfatizar temas ligados ao campo econômico liberal. Da análise sobre a política econômica presente no discurso programático das agremiações de esquerda da América Latina, portanto, destaca-se a resistência em aderir de maneira incondicionada aos dispositivos do Consenso de Washington. Além disso, 15 casos - incluído o PSUV - apresentam uma agenda com quatro ou mais ênfases em SD. Este dado demonstra 0 interesse dos partidos em desenvolver propostas de orientação social-democrata, ainda que PLD e PNP defendam concomitantemente um conjunto de propostas liberais.

Quatro partidos de esquerda deram três ou mais ênfases em LIB: PLD, UNE, APRA e PNP. Destes, apenas o último se manteve no campo positivo do I-SD. 0 colombiano PLC realizou três ênfases, duas SD e uma LIB. Este conjunto de cinco partidos, portanto, parece mais suscetível a não priorizar os objetivos econômicos social-democratas em seus discursos programáticos, especialmente pela adesão 
de propostas contrárias. Para este conjunto, quatro ênfases LIB foram observadas três vezes cada: flexibilização das relações de trabalho, disciplina fiscal/superávit, controle de inflação e abertura ao investimento estrangeiro. A análise dos partidos de direita não permite inferências para seu conjunto na América Latina, mas aponta para clara divergência com os partidos de esquerda: dois deles enfatizaram um número elevado de temas LIB e apenas um desses realizou ênfases SD. 0 único tema liberal não enfatizado nenhuma vez neste grupo, nem em toda a amostra, é a privatização de empresas públicas do sistema produtivo.

\section{CONCLUSÕES: A ESQUERDA LATINO-AMERICANA CONTEMPORÂNEA}

Destacadas na introdução, quatro perguntas orientaram o desenvolvimento desta pesquisa. Até o momento, foram desenvolvidos argumentos relativos a duas delas: os partidos de esquerda latino-americanos possuem um discurso de identidade de classe em seus programas e estão orientados majoritariamente para políticas econômicas social-democratas. Nesta conclusão se procura identificar a relação entre identidade de classe e políticas social-democratas nos discursos programáticos; e se existe um padrão geral nestes temas entre a esquerda latinoamericana. É necessário ressalvar, entretanto, que os programas estudados cobrem um período de dez anos entre os diferentes casos. Considerando diversos fatores, como o impacto das disputas eleitorais e as alterações no contexto econômico internacional e nacional, não é improvável que os partidos alterem suas proposições programáticas em espaço de tempo relativamente curto. Portanto, a interpretação dos dados apresentados neste estudo, como uma fotografia para os partidos de esquerda da América Latina nos anos 2000, não deve descuidar dos diferentes tempos em que cada programa foi gerado (conforme o Quadro 1, acima).

Para analisar a relação entre identidade de classe e políticas socialdemocratas, o quadro abaixo apresenta a correlação entre o I-LC e o I-SD para os partidos de esquerda, para apenas os partidos que obtiveram um I-SD positivo e para todos os casos exceto o super desviante PLD.

\begin{tabular}{|l|c|c|c|}
\hline \multicolumn{4}{|c|}{ Quadro 4 - Correlação I-LC x I-SD } \\
\hline & Toda esquerda & $\begin{array}{c}\text { Campo I-SD } \\
\text { positivo }\end{array}$ & $\begin{array}{c}\text { Excluído } \\
\text { apenas PLD }\end{array}$ \\
\hline R0 de Spearman Coef. de Correlação &, 732 &, 718 &, 803 \\
\hline Sig. Unilateral &, 000 &, 001 &, 000 \\
\hline Número de casos & 19 & 16 & 18 \\
\hline Correlação signific. ao nível de & .01 & .01 & .01 \\
\hline
\end{tabular}

Os DISCURSOS PROGRAMÁTICOS DOS PARTIDOS POLÍTICOS... 
Pode-se observar que existe correlação entre I-LC e I-SD quando considerados todos os partidos de esquerda, que se mantém quando tomados apenas os partidos do campo positivo do I-SD ${ }^{5}$. Sem o desviante PLD a análise traria um nível de correlação bastante forte. De qualquer forma, todos os recortes exibem correlação positiva e apreciável. Este achado permite inferir que no discurso programático dos partidos de esquerda da América Latina existe uma relação positiva entre o discurso de classe e a proposição de políticas econômicas socialdemocratas, consideradas também como resistência às políticas neoliberais. Pode indicar, em decorrência, que para o conjunto dos partidos estudados a associação com a classe social não é um apelo vazio: existe uma relação clara entre o espaço que 0 apelo de classe recebe e as iniciativas de política econômica ligadas aos interesses redistributivos da classe trabalhadora.

Quanto ao tipo de documento, a diferença mais relevante parece ser a seguinte: programas aprovados em congressos defendem I-LC e I-SD mais elevados do que os documentos elaborados por técnicos. As médias de I-LC/I-SD dos primeiros é de 5,2/5,4 e, para os documentos técnicos, é de 3,6/1,9. A proposição de May (1973) a respeito da disparidade ideológica entre os setores internos dos partidos oferece uma explicação para esta constatação. Lideranças intermediárias - provavelmente representadas nos congressos das agremiações - podem ser sensivelmente mais radicais do que os líderes nacionais interessados em um apelo eleitoral mais universal e, portanto, por programas políticos mais centristas. Estas observações abrem possibilidade de pesquisas futuras, com maior atenção às variações temporais e aos diferentes momentos do discurso programático em cada partido.

Por fim, cumpre destacar os padrões encontrados no cruzamento entre I-LC e I-SD para os partidos latino-americanos. Nesta etapa do estudo foram localizadas aproximações e divergências interessantes entre os partidos de esquerda, algumas nem sempre reparadas na literatura. 0 gráfico abaixo apresenta a localização das agremiações nas escalas trabalhadas.

\footnotetext{
${ }^{5}$ Calculada a correlação de Pierson, obtêm-se igualmente coeficientes de correlação expressivos e positivos, de respectivamente: ,683 (19 casos); ,775 (16 casos); e ,816 (18 casos). Todas as correlações significativas ao nível de ,01 (unilateral). Os testes apontam para a existência de um relacionamento significativo e positivo entre as variáveis: I-LC e I-SD aumentam de forma relativamente conjunta, como pode ser visualizado nos gráficos 1 e 2 .
} 


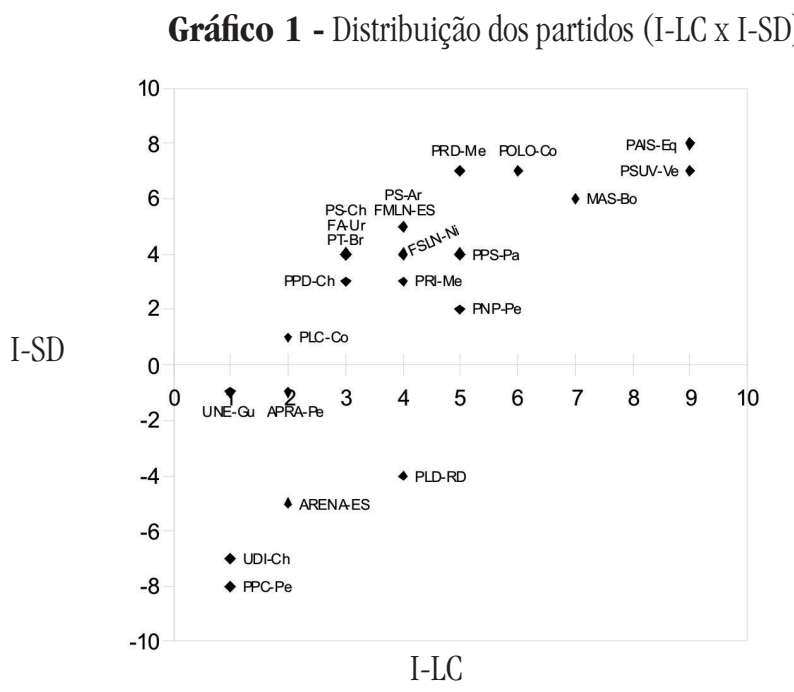

Os partidos de direita, como o esperado, ocupam o canto inferior esquerdo do gráfico, área de ênfase restrita na luta de classes (nível baixo) e políticas econômicas liberais. Ainda no campo negativo aparece o PLD, o principal caso desviante da análise, pois ao mesmo tempo adere à luta de classes e defende uma política econômica predominantemente liberal. Cabe destacar que seu documento é o mais antigo (do ano 2000) e também o mais longo. Observando o programa mais de perto, verifica-se que a análise está correta: em diversos momentos o partido se compromete com a melhora nas condições de vida dos setores pobres do país caribenho, mas as medidas propostas são políticas sociais ou microeconômicas. No campo macroeconômico, predomina o discurso liberal: "estimular y facilitar el cambio del modelo proteccionista a la libre competencia", "estimular la inversión privada, manter la estabilidad macroeconómica y promover la inversión extrangera" (PRD-RD, 2000, p. 16-17). A agremiação exemplifica a possibilidade de um sistema econômico orientado por metas liberais que procuram resgatar a proteção social e o combate à desigualdade com políticas sociais. Um estudo mais aprofundado do caso e a localização de experiências semelhantes - talvez em programas de coalizões - podem orientar futuras análises.

UNE, PLC e APRA formam um grupo que pode ser identificado por baixa mobilização da identidade de classe e baixa adesão às políticas social-democratas. Tratam-se, portanto, de partidos que tendem a uma posição econômica centrista com apelos não orientados pela identidade de classe. Pode-se destacar, ainda, que são partidos selecionados pela vinculação à Internacional Socialista e que governam ou já governaram seus países. Ademais, PLC e APRA competem com

Os DISCURSOS PROGRAMÁTICOS DOS PARTIDOS POLÍTICOS...

A. Oliveira $\bullet 217$ 
outros dois partidos analisados (POLO e PNP), que se posicionam em um nível maior de I-LC e I-SD. 0 campo positivo do gráfico merece uma análise focalizada.

Gráfico 2 - Campo positivo (I-LC x I-SD)

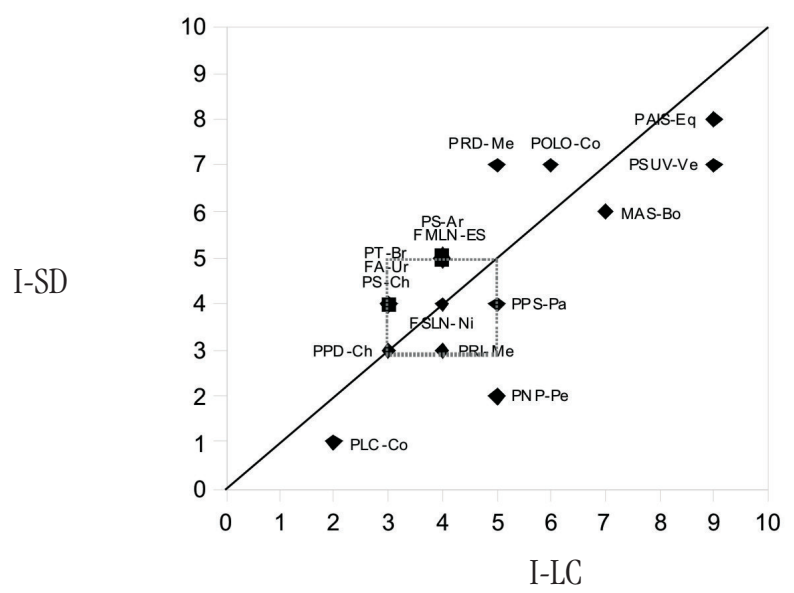

No campo positivo existe expressiva relação entre I-LC e I-SD. 0 gráfico expõe a existência de um grupo de nove partidos que se localizam entre as posições 3, 3 e 5, 5 e se separam em no máximo três níveis, formado por PPD, PT, PS-Ch, FA, PRI, FSLN, FMLN, PS-Ar e PPS. São partidos de esquerda ou centro-esquerda atentos às questões de classe e comprometidos com uma política econômica de orientação social-democrata. Com exceção do partido paraguaio, PPS, todos os demais permanecem no nível médio baixo do I-LC, o que na classificação adotada indica a percepção de interesses contraditórios entre o capital e o trabalho - mas não adota a idéia de exploração ou dominação. Em seus discursos programáticos, os partidos do quadrante destacado assumem uma posição favorável ao campo popular ou trabalhador e, em matéria de política econômica, desenvolvem estratégias que associam o interesse global da sociedade à melhora gradual das condições sociais e econômicas destes setores.

O PNP é um caso parcialmente desviante, pois seu I-SD é menor do que seria o esperado a partir de sua adesão à luta de classes em nível médio alto. Consta a presença em seu discurso programático de quatro ênfases LIB e seis SD, sendo que algumas propostas que pareciam ênfases social-democratas não foram consideradas, como no caso em que defende uma nacionalização na área do petróleo que na verdade não implica estatização das empresas (PNP-Pe, 2006, p. 65). Por outro lado, enfatiza também questões de uma agenda social-democrata, como a importância do mercado interno e da geração de trabalho para fomentar 
o crescimento econômico e a distribuição de riqueza (PNP-Pe, 2006, p. 27). Visto em conjunto, o discurso programático do PNP pode ser considerado contraditório. Um estudo de caso poderia verificar em que medida se trata de um partido com divergências ideológicas ou em transição.

0 PRD e o POLO aparecem no centro superior do gráfico. São partidos que realizam um consistente apelo à luta de classes em seus programas e, ao mesmo tempo, propõem um amplo conjunto de propostas econômicas social-democratas. Em comum, os partidos dividem o fato de serem atores menores em seus sistemas políticos, competindo com agremiações de direita e também com partidos mais centristas como, respectivamente, o PRI e o PLC - embora o PRD seja bastante mais relevante do que o POLO, tendo inclusive superado o PRI em algumas eleições.

Com elevado I-LC, encontram-se no canto superior direito do gráfico MAS, PAIS e PSUV. Antes de considerá-los um grupo, é necessário lembrar, como destacado anteriormente, que o PSUV apresentou uma discrepância significativa no I-SD. Mesmo com uma distância de quatro níveis, superior à encontrada no grupo de nove partidos, é possível considerar que MAS e PAIS se assemelham por julgar que a partir do governo é possível implementar políticas que fortalecem a posição da classe popular, sem a eliminação da propriedade privada dos meios de produção. Mesmo assim, o PAIS é consideravelmente mais radical em seus propósitos de mudanças econômicas. 0 MAS desenvolve um discurso programático de tipo social-democrata, como também ressalta Reis (2010).

A pesquisa permite afirmar que o discurso programático da esquerda latino-americana contemporânea se organiza de maneira coerente: uma maior identidade com a classe trabalhadora corresponde, no campo da política econômica, a maior adesão às propostas da social-democracia e menor adesão ao neoliberalismo. Ou seja, quanto mais os partidos estudados identificam a existência de contradição entre classes sociais, mais eles se preocupam com formas de regulamentar as relações econômicas e promover redistribuição de recursos. A pesquisa também permite concluir que a esquerda da América Latina contemporânea desenvolve predominantemente uma visão social-democrata moderada em seu discurso programático. Com algumas exceções, os partidos de esquerda analisados não adotam os princípios ideológicos e as políticas prescritas pelo Consenso de Washington, mas também não propõem transformações radicais no sistema socioeconômico de seus países. É possível inferir que, enfrentando a hegemonia do pensamento neoliberal na década de 1990, os partidos de esquerda latino-americanos preservaram a capacidade de divergir e propor soluções alternativas em matéria de política econômica. 


\section{REFERÊNCIAS}

CLARK, Terry Nichols. The breakdown of class politics. The American Sociologist, Washington, v. 34, n. 1-2, p. 17-32, 2003.

DUVERGER, Maurice. Os partidos políticos. Rio de Janeiro: Zahar, 1970.

ESPING-ANDERSEN, Gosta. The three worlds of welfare capitalism. Princeton: Princeton University, 1998.

KITSCHELT, Herbet. Class structure and social democratic party strategy. British Journal of Political Science, Cambridge, n. 23, p. 299-337, 1993.

Klingemann, Hans-Dieter; Hofferbert, Richard I; Budge, Ian. Parties, policies, and democracy. Oxford: Westview, 1994.

LIPSET, Seymour Martin; ROKKAN, Stein. Estruturas de clivagem, sistemas partidários e alinhamentos de eleitores. In: LIPSET, Seymour Martin. Consenso e conflito: ensaios de sociologia política. Lisboa: Gradiva, 1992. p. 161-259.

MARX, Karl; ENGELS, Friederich. Manifesto do partido comunista. Lisboa: Avante, 1997.

MAY, John D. Opinion structure of political parties: the special law of curvilinear disparity. Political Studies, Newcastle-upon-Tyne, n. XXI, p. 135-51, 1973.

NOTERMANS, Ton. Money, markets, and state: social democratic economic policies since 1918. Cambridge: Cambridge University, 2000.

OLIVEIRA, Augusto Neftali Corte de. Partidos e política social no Brasil e no Chile. Revista Debates, Porto Alegre, v. 3, n. 2, p. 39-67, 2009.

PREZEWORSKI, Adam. Capitalismo e social-democracia. São Paulo: Companhia das Letras, 1989.

REIS, Guilherme Simões. A social-democracia do MAS: nem revolução, nem populismo na Bolívia. In: ENCONTRO ANUAL DA ASSOCIAÇÃO NACIONAL DE PÓSGRADUAÇ̧̃̃O E PESQUISA EM CIÊNCIAS SOCIAIS, 34., 2010, Caxambu. Anais... Disponível em: $\quad$ http://www.anpocs.org.br/portal/index.php?option=com_ wrapper\&Itemid=90>. Acesso em: 10 jan. 2011.

Rodrik, Dani. Goodbye Washington consensus, hello Washington confusion? Journal of Economic Literature, Pittsburgh, v. 44, n. 4, p. 973-987, 2006.

\section{DOCUMENTOS PARTIDáRIOS}

APRA-PE. Plan de gobierno 2006-2011. Lima: Partido Aprista Peruano, 2006.

ARENA-ES. País seguro: plan de gobierno 2004-2009. San Salvador: ARENA, 2004. 
FA-UR. Propuestas para seguir construyendo un país de primera. Montevidéu: Frente Amplio, 2009.

FMLN-ES. Programa de gobierno: 2009-2014. San Salvador: FMLN, 2009.

FSLN-NI. Programa del gobierno de reconciliacion y Unidad Nacional. 2006. Disponível em: <http://americo.usal.es/oir/opal/Documentos/Nicaragua/FSLN/ Programa\%20de\%20Gobierno,\%20Campaña\%202006.pdf>. Acesso em: 8 jan. 2011. MAS-B0. Programa de gobierno: 50 propuestas concretas para encarar la crisis. La Paz: MAS, 2005.

PAIS-EQ. Princípios y programa. Quito: Alianza País, 2010.

PLC-CO. Veinte propuestas para garantizar la igualdad de oportunidades y el bienestar de los colombianos. Bogotá: PLC, 2010.

PLD-RD. Programa de gobierno. San Domingo: PLD, 2000.

PNP-PE. Plan de gobierno. Villa El Salvador: PNP, 2006.

POLO-CO. Conclusiones y relatorías del segundo Congreso Nacional del Polo Democrático Alternativo. Bogotá: Polo, 2009.

PPC-PE. Plan de gobierno. 2005. Disponível em: <http://americo.usal.es/oir/opal/ Documentos/Perú/PPC/PlandeGobierno\%20(2006).pdf>. Acesso em: 10 jan. 2011.

PPD-CH. Ideas y valores progresistas. Santiago: PPD, 2003.

PPS-PA. Base ideológica e marco programático. Assunção: PPS, 2002.

PRD-ME. Programa del partido de La Revolución Democrática. Cidade do México: PRD, 2009.

PRD-RD. Programa de gobierno. Santo Domingo: PRD, 2000.

PRI-ME. Plataforma electoral federal 2009-2012. Cidade do México: PRI, 2009. PS-AR. Diez puntos programáticos. Buenos Aires: PS, 2010.

PS-CH. Resoluciones del XXVIII congreso general ordinario. Panimávida: PS, 2008. PSUV-VE. Libro Rojo. Caracas: PSUV, 2010.

PT-BR. Resoluções sobre as diretrizes deprograma 2011/2014. 2010. Disponível em: $\quad<$ http://www.pt.org.br/portalpt/noticias/eleicoes-2010-11/leia-resolucaoaprovada-pelo-40-congresso-sobre-diretrizes-do-programa-de-governo-3264. html>. Acesso em: 10 jan. 2011.

UDI-CH. Chile hacia el bicentenario: nuestra propuesta. Santiago: UDI, 2005.

UNE-GU.Programa de gobierno. 2006. Disponível em: <http://americo.usal.es/oir/opal/ Documentos/Guatemala/UNE/Programagobierno2006.pdf>. Acesso em: 11 jan. 2011. 